\title{
A abordagem do portal de notícias G1 frente aos casos de denúncias de assédio sexual contra Harvey Weinstein e Kevin Spacey
}

\author{
El enfoque del portal de noticias G1 frente a los casos de denuncias de \\ acoso sexual contra Harvey Weinstein y Kevin Spacey \\ The G1 news portal approach to cases of sexual harassment allegations \\ against Harvey Weinstein and Kevin Space
}

Jéssica Corrêa Pereira ${ }^{1}$

\begin{abstract}
Resumo
Em outubro de 2017, personalidades e funcionários da indústria do entretenimento norte-americana declararam terem sido vítimas de assédio sexual nesse ramo. Além das denúncias, campanhas de apoio e contra o assédio foram realizadas, dando destaque ao tema na mídia nacional e internacional. Em vista da relevância e atualidade da repercussão, este trabalho pretendeu analisar como é a abordagem dos veículos jornalísticos digitais do Brasil quando noticiam essas denúncias de assédio sexual, a partir da recolha das matérias no portal de notícias G1 a respeito das denúncias contra os acusados Harvey Weinstein e Kevin Spacey. A pesquisa seguiu a linha metodológica da análise de conteúdo, visando coletar dados quantitativos e qualitativos da veiculação jornalística de denúncias de assédio sexual com caráter hétero e homossexual. E, principalmente, investigar como essa violência é apresentada ao público e, em especial, se acontece o esclarecimento acerca das suas formas de manifestação e as suas possibilidades de combate ou denúncia. Para discutir estas questões, a pesquisa salientou as múltiplas manifestações de violência e como elas podem ser promovidas em apoio uma a outra e de forma colaborativa na e pela sociedade, relacionando o potencial do discurso com as questões de gênero e o machismo. Com base nos resultados alcançados, a pesquisa verificou como o jornalismo apresenta a capacidade de produzir, reproduzir ou romper com o discurso. Nesse âmbito, o trabalho conferiu que a profissão não vem atuando como no último caso, havendo a falta de um posicionamento contrário às violências e a favor da responsabilidade social.
\end{abstract}

Palavras-chaves: assédio sexual; jornalismo digital; violência sexual.

\section{Resumen}

En octubre de 2017, personalidades y funcionarios de la industria del entretenimiento norteamericana declararon haber sido víctimas de acoso sexual en esa rama. Además de las denuncias, campañas de apoyo y contra el acoso se realizaron, destacando el tema en los medios nacionales e internacionales. En vista de la relevancia y actualidad de la repercusión, este trabajo pretendió analizar cómo es el abordaje de los vehículos periodísticos digitales de Brasil cuando notician esas denuncias de acoso sexual, a partir de la recogida de las materias en el portal de noticias G1 acerca de las denuncias contra los acusados Harvey Weinstein y Kevin Spacey. La investigación siguió la línea metodológica del análisis de contenido, buscando recoger datos cuantitativos y cualitativos de la transmisión periodística de denuncias de acoso sexual con carácter heterosexual y homosexual. $\mathrm{Y}$, principalmente, investigar cómo esa violencia es presentada al público y, en especial, si ocurre el esclarecimiento acerca de sus formas de manifestación y sus posibilidades de combate o denuncia. Para discutir estas cuestiones, la investigación subrayó las múltiples manifestaciones de violencia y cómo ellas pueden ser promovidas en apoyo a la otra y de forma colaborativa en la sociedad y relacionando el potencial del discurso

\footnotetext{
${ }^{1}$ Bacharel em Jornalismo; Universidade Federal de Pelotas - UFPel; Pelotas, Rio Grande do Sul, Brasil; jesscorreapereira@hotmail.com.
} 
con las cuestiones de género y el machismo. Con base en los resultados alcanzados, la investigación verificó cómo el periodismo presenta la capacidad de producir, reproducir o romper con el discurso. En este ámbito, el trabajo ha conferido que la profesión no viene actuando como en el último caso, habiendo la falta de un posicionamiento contrario a las violencias ya la responsabilidad social.

Palabras claves: acoso sexual; periodismo digital; violencia sexual.

\begin{abstract}
In October 2017, personalities and entertainment industry officials said they had been sexually harassed. Besides the denunciations, campaigns of support and against the harassment were carried out, giving prominence to the subject in the national and international media. In view of the relevance and timeliness of the repercussion, this paper intends to analyze the approach of the Brazilian journalistic vehicles when reporting these reports of sexual harassment, from the collection of the stories in the G1 news portal regarding the accusations against the accused Harvey Weinstein and Kevin Spacey. The research followed the methodological line of content analysis, aiming to collect quantitative and qualitative data of journalistic reporting of sexual harassment denunciations with heterosexual and homosexual character. Above all, investigate how this violence is presented to the public and, in particular, whether there is clarification about its forms of manifestation and its possibilities of combat or denunciation. In order to discuss these issues, the research highlighted the multiple manifestations of violence and how they can be promoted in support of one another and in a collaborative way in and through society, relating the potential of discourse with gender issues and machismo. Based on the results achieved, the research verified how journalism presents the capacity to produce, reproduce or break with the discourse. In this context, the work showed that the profession is not acting as in the last case, lacking a position contrary to violence and in favor of social responsibility.
\end{abstract}

Keywords: sexual harassment; digital journalism; sexual violence.

\title{
1. Introdução
}

No decorrer do segundo semestre de 2017, inúmeras denúncias de casos de assédio sexual foram realizadas e divulgadas em veículos de comunicação, nas mídias e redes sociais online. O incentivo para esse importante movimento, que repercutiu em diversos lugares do mundo e atingiu pessoas de diferentes classes sociais, surgiu das denúncias de casos polêmicos de assédio e agressão sexual envolvendo personalidades e funcionários da indústria do entretenimento norte-americana. Por conta da ampla midiatização desses casos, cada vez mais essas violências têm sido apresentadas em portais de notícias e procuradas pelos internautas, como aponta o site de monitoramento Me Too Rising.

Em especial, o tema não se limita a abordagem pelos veículos jornalísticos, mas também é discutido dentro da esfera pública e aponta diferentes percepções. De forma semelhante também acontece no contexto digital, por conta da facilidade para o acesso à informação e a interatividade que é promovida pelos portais de notícias, possibilitando que esses espaços também sirvam para a discussão do público e que possam ser conferidas essas divergentes opiniões acerca de casos de violência sexual e de gênero, sendo manifestadas 
pelos internautas nas áreas específicas para comentários nas mídias e redes sociais, principalmente quando surgem matérias tratando desses casos.

Em vista do papel social do jornalismo não somente como difusor da informação, mas também como promotor do conhecimento, este trabalho pretende analisar como é a abordagem dos veículos jornalísticos digitais no Brasil quando noticiam denúncias de assédio sexual, tendo como objetivo investigar como é realizada a apresentação dessa violência ao público online e se existe o esclarecimento acerca das suas formas de manifestação e as suas possibilidades de combate ou denúncia. Para tanto, será verificada a cobertura jornalística das acusações contra os norte-americanos Harvey Weinstein e Kevin Spacey, a escolha desses casos decorreu da atualidade dos acontecimentos, pelas denúncias terem sido veiculadas entre um intervalo curto de tempo e por tratarem-se de relações hétero e homossexuais, permitindo conferir as semelhanças e diferenças na construção do discurso jornalístico para ambas notícias.

Com esse intuito, o trabalho pretende utilizar da metodologia da análise de conteúdo, especificamente nas abordagens das matérias que foram realizadas pelo portal de notícias das Organizações Globo, intitulado como G1 - O portal de notícias da Globo. De acordo com a lista do site Alexa, dentre os 50 sites brasileiros mais acessados no ano de 2017, o site da Globo destaca-se em $5^{\circ}$ lugar no ranking. Logo, a escolha dessa organização como macro objeto da pesquisa justifica-se pelo caráter jornalístico e o índice de audiência elevado (fácil acesso do público), além da procura em atuar em diversas redes sociais, possibilitando com que o conteúdo do site tenha diversos meios de compartilhamento pelo público, bem como garantindo com que o próprio veículo de comunicação esteja integrado sobre o que está sendo repercutido na web. Por conta da abrangência de segmentos do site de notícias, a pesquisa foca no seu portal interno destinado à prática do jornalismo.

Para além da questão quantitativa, o trabalho também pretende englobar a análise qualitativa frente a abordagem utilizada pelo portal de notícias na produção dos conteúdos que tratam das denúncias dos casos de assédio sexual. Em razão disso, serão discutidos os conceitos de violência e discurso, bem como as suas diversas possibilidades de manifestação e suas relações de acordo com os contextos histórico-culturais, voltando-se às consequências da cultura machista e patriarcal na sociedade, para contextualizar com o tema da violência de gênero e sexual. Enfim, o trabalho tem como objetivo ressaltar como o jornalismo digital relaciona-se com a violência em seus diversos âmbitos.

A relevância desse tema de pesquisa encontra-se na análise da atuação digital dos veículos jornalísticos brasileiros frente a busca pela mudança do cenário da indústria do 
entretenimento norte-americana, bem como das demais indústrias e espaços que sejam acometidos pelo assédio sexual. A partir da pesquisa, o trabalho investiga como a profissão está utilizando do seu potencial de combate a essa violência e das potencialidades que estão presentes no ambiente digital.

\section{As matérias}

Em vista do problema de pesquisa proposto no trabalho, realizou-se no portal de notícias G1 a coleta e a organização dos conteúdos que tratavam acerca das denúncias de assédio e agressão sexual contra Harvey Weinstein (cerca de 40 notícias) e Kevin Spacey (cerca de 21 notícias), durante o período de outubro e novembro de 2017. A partir do agrupamento desses conteúdos, análises superficiais foram realizadas no título e texto de cada matéria, visando selecionar as duas publicações que seriam utilizadas como objetos da análise de conteúdo desse trabalho. Tendo sido escolhidas as matérias intituladas como Angelina Jolie, Gwyneth Paltrow e mais atrizes dizem a jornal que foram assediadas por Harvey $W_{\text {Winstein }}^{2}$ e Kevin Spacey recebe mais 20 acusações de "comportamento inapropriado" em teatro londrino ${ }^{3}$. Os motivos que envolvem a escolha dessas matérias estão pautados nas semelhanças entre elas, a exemplo de ambas publicações tratarem a respeito da existência de um número substancial de denúncias contra os acusados.

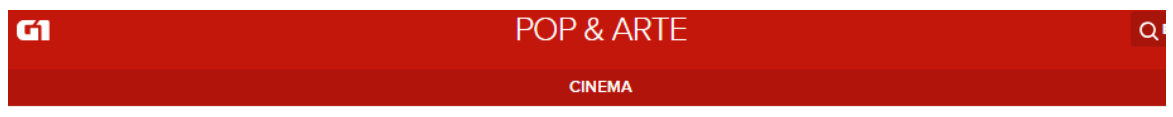

\section{Angelina Jolie, Gwyneth Paltrow e mais atrizes dizem a jornal que foram assediadas por Harvey Weinstein}

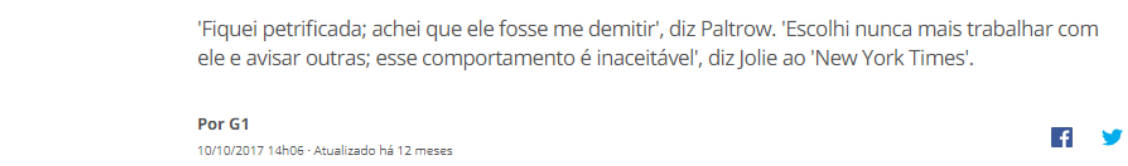

Figura 1 - Captura de tela do cabeçalho da matéria sobre as denúncias contra Harvey Weinstein Fonte: G1

\footnotetext{
${ }^{2}$ https://g1.globo.com/pop-arte/cinema/noticia/angelina-jolie-e-gwyneth-paltrow-dizem-que-foram-assediadaspor-harvey-weinstein-diz-jornal.ghtml. Publicada em 10 de out. de 2017. Acesso em jun. de 2018. ${ }^{3}$ https://g1.globo.com/pop-arte/noticia/kevin-spacey-recebe-mais-20-acusacoes-de-comportamentoinapropriado-em-teatro-londrino.ghtml. Publicada em 16 de nov. de 2017. Acesso em jun. de 2018.
} 


\section{Kevin Spacey recebe mais 20 acusações de 'comportamento inapropriado' em teatro londrino}

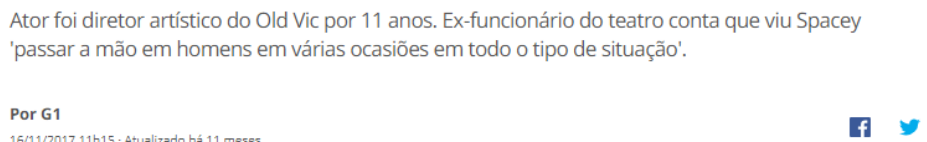

Figura 2 - Captura de tela do cabeçalho da matéria sobre as denúncias contra Kevin Spacey Fonte: G1

As matérias também foram produzidas pelo próprio G1 e cada uma possui como fonte jornais internacionais, no caso da notícia a respeito do Harvey Weinstein foi utilizado o jornal norte-americano "New York Times" e sobre o Kevin Spacey, o jornal britânico "The Guardian". Além disso, apesar de ambas matérias abordarem sobre casos de assédio sexual, elas estão anexadas na categoria "Pop \& Arte" do portal de notícias, a atitude acaba por descaracterizar o tema criminal das matérias e favorece o caráter de espetáculo midiático entorno dos casos.

As semelhanças também estão presentes no espaço destinado para o corpo do texto, possuindo relação com o design estrutural das matérias. Por exemplo, os relatos das vítimas e testemunhas de cada caso receberam forte destaque na formatação do texto, a partir da escrita com uma fonte maior quando comparada ao restante da notícia, bem como em negrito e na posição centralizada da página. Através dessas atitudes, o portal de notícias oferece um caráter mais apelativo ao conteúdo das matérias e, consequentemente, atrai a maior atenção do público para a leitura. Conforme mostram a figura 3 e a figura 4 abaixo:

\section{"Eu era uma criança, tinha acabado de assinar o contrato e fiquei petrificada", ela disse.}

\footnotetext{
A atriz diz que recusou o assédio e contou ao seu namorado na época, Brad Pitt. Ele teria confrontado o produtor e dito para que ele nunca mais tocasse nela. Harvey pediu para que ela não contasse nada a ninguém. "Eu achei que ele fosse me demitir", ela disse. Brad Pitt confirmou o relato ao "New York Times".
}

Figura 3 - Captura de tela do destaque oferecido ao relato de uma vítima de Harvey Weinstein Fonte: G1 


\title{
"Eu o vi passar a mão em homens em várias ocasiões em todo o tipo de situação \\ (...) Se aproveitava do fato de ser uma grande estrela. Tocava os homens entre as pernas, fazendo rapidamente para que não pudessem se afastar de seu caminho".
}

\author{
Em comunicado, o Old Vic afirma que havia um "culto à personalidade" em torno \\ de Kevin Spacey durante seu tempo como diretor do teatro, e que sua fama \\ impediu jovens atores e funcionários de denunciá-lo.
}

Figura 4 - Captura de tela do destaque oferecido ao relato de uma testemunha contra Kevin Spacey Fonte: G1

\section{Método de análise}

A linha metodológica da pesquisa é a análise de conteúdo, visando analisar como é a abordagem dos veículos jornalísticos digitais no Brasil quando noticiam denúncias de assédio sexual. Para ser realizada a análise foram escolhidas as matérias que tratam acerca das denúncias desse crime contra os acusados Harvey Weinstein e Kevin Spacey, utilizando como macro objeto de pesquisa o portal de notícias G1. Neste trabalho, será compartilhado do conceito para a análise de conteúdo da autora Laurence Bardin (1974), como sendo:

Um conjunto de técnicas de análise das comunicações visando obter, por procedimentos, sistemáticos e objetivos de descrição do conteúdo das mensagens, indicadores (quantitativos ou não) que permitam a inferência de conhecimentos relativos às condições de produção/recepção (variáveis inferidas) destas mensagens (BARDIN, 1979, p. 42).

O trabalho pretende obter dados quantitativos e qualitativos a respeito das matérias Angelina Jolie, Gwyneth Paltrow e mais atrizes dizem a jornal que foram assediadas por Harvey Weinstein e Kevin Spacey recebe mais 20 acusações de "comportamento inapropriado" em teatro londrino, para explorar quais termos, expressões e informações, o portal de notícias brasileiro está utilizando na construção dos textos jornalísticos sobre assédio sexual. A princípio, todas as categorizações realizadas no trabalho configuram-se como a posteriori, elaboradas após a análise do material, como ressalta Bardin (1979).

Na primeira etapa para dar andamento à análise de conteúdo, duas pesquisas separadas foram realizadas com os nomes "Harvey Weinstein" e "Kevin Spacey" no próprio buscador de conteúdo oferecido pelo portal de notícias G1, visando coletar todas as matérias que tratam a respeito dos dois casos e que foram divulgadas no período de outubro e novembro de 2017. 
Em seguida, todas as matérias (produções textuais) do G1 que estão dentro do período de tempo proposto e que abordam sobre o tema de denúncias, assédio e agressão sexual, foram recolhidas e divididas em duas categorias, de acordo com os nomes dos acusados que elas estão abordando. Então, uma breve análise dos conteúdos foi realizada para identificar aquelas que apresentam semelhanças na construção jornalística e nos acontecimentos veiculados, visando selecionar uma matéria de cada agrupamento para servirem como alvos da pesquisa.

Nesta fase de verificação das semelhanças entre os conteúdos, o trabalho também teve como base a análise jornalística, buscando identificar as categorias em que foram anexadas as matérias no portal de notícias e verificar as suas origens, para conferir se o conteúdo foi produzido pelo próprio G1, extraído de outros meios de comunicação ou enviado por colaboradores, identificando os números e os tipos de fontes informativas.

Na etapa seguinte do trabalho, os números de palavras nos títulos, nas linhas de apoio e no corpo dos textos de cada matéria foram contabilizados. Destacando ainda, os números de ilustrações, hiperlinks e comentários que ajudaram a compor as matérias. A partir disso, uma tabela com os dados coletados foi elaborada, possibilitando conferir como ocorreu a construção das matérias pelo portal de notícias e considerar o nível de profundidade oferecido para cada caso, viabilizando ainda que fosse realizada a comparação entre as duas estruturas.

Na segunda etapa de quantificação dos conteúdos, a contagem da repetição de certas palavras ou até mesmo família de palavras foi realizada. Em seguida, visando descobrir a abordagem dos veículos jornalísticos digitais no Brasil quando noticiam denúncias de assédio sexual, foram elencados e quantificados os termos utilizados pelo portal de notícias para fazer menção às vítimas, aos acusados e à divulgação dos crimes, bem como as palavras que surgiram para descrever os atos dos crimes e o comportamento dos acusados. A partir da recolha dos termos, eles foram colocados em mais uma tabela do trabalho e apresentados de acordo com a categoria que se relacionam, para melhor visualização e comparação dos dados. Segundo Ringoot (2006), a quantificação de itens também se configura como a ideia principal da metodologia da análise de conteúdo. Pois, permite evidenciar os assuntos e os temas mais importantes contidos nas mensagens midiáticas.

$\mathrm{Na}$ análise qualitativa do trabalho, os termos recolhidos durante a análise de conteúdo são discutidos de forma a verificar se a abordagem do portal de notícias tende para um teor criminal ou mais informal, havendo a espetacularização ou a suavização dos fatos. Nesta etapa, as análises compreendem as palavras e expressões tanto do título e da linha de apoio quanto do corpo do texto, levando em consideração os seus significados apontados no dicionário Michaelis e as questões de gênero estudadas para o trabalho. 
Em seguida, a pesquisa buscou verificar a narrativa dos crimes para analisar se aconteceu o desmerecimento das vítimas e/ou do próprio crime durante a abordagem. Além disso, a análise estende-se para verificar como o portal de notícias se apropriou do discurso de suas fontes para a construção jornalística, visando identificar como acontece a produção e reprodução do discurso também por meio dessa prática profissional.

Bardin (1979, p. 40) aponta que "qualquer análise de conteúdo não visa o estudo da língua ou da linguagem, mas sim a determinação mais ou menos parcial do que chamaremos as condições de produção dos textos, que são o seu objeto". Logo, por meio das análises que foram realizadas, o trabalho pretendeu justamente verificar quais foram essas condições de produção dos textos para as matérias acerca do crime de assédio sexual.

\section{Análise de conteúdo}

$\mathrm{Na}$ análise quantitativa dos títulos, a matéria Angelina Jolie, Gwyneth Paltrow e mais atrizes dizem a jornal que foram assediadas por Harvey Weinstein contabiliza 16 palavras com 88 caracteres sem espaços. Já a matéria Kevin Spacey recebe mais 20 acusações de “comportamento inapropriado" em teatro londrino contabiliza 12 palavras com 77 caracteres sem espaços.

$\mathrm{Na}$ linha de apoio da matéria sobre o caso de Harvey Weinstein, 29 palavras com 158 caracteres sem espaços compõem as frases "Fiquei petrificada; achei que ele fosse me demitir", diz Paltrow. "Escolhi nunca mais trabalhar com ele e avisar outras; esse comportamento é inaceitável", diz Jolie ao "New York Times". Na segunda matéria analisada, a linha de apoio traz as seguintes frases Ator foi diretor artístico do Old Vic por 11 anos. Ex-funcionário do teatro conta que viu Spacey "passar a mão em homens em várias ocasiões em todo o tipo de situação”, contabilizando 31 palavras com 137 caracteres sem espaços.

Tabela 1 - Estrutura das matérias analisadas do G1

\begin{tabular}{|c|c|c|c|c|c|c|}
\hline \multirow{3}{*}{$\begin{array}{l}\text { Angelina Jolie, Gwyneth } \\
\text { Paltrow e mais atrizes } \\
\text { dizem a jornal que foram } \\
\text { assediadas por Harvey } \\
\text { Weinstein }\end{array}$} & \multicolumn{3}{|c|}{ Número de palavras } & \multicolumn{3}{|c|}{ Número de } \\
\hline & Título & $\begin{array}{c}\text { Linha de } \\
\text { apoio }\end{array}$ & $\begin{array}{c}\text { Corpo do } \\
\text { texto }\end{array}$ & Ilustrações & Hiperlinks & Comentários \\
\hline & 16 & 29 & 453 & 4 & 2 & 46 \\
\hline $\begin{array}{l}\text { Kevin Spacey recebe mais } \\
20 \text { acusações de } \\
\text { "comportamento } \\
\text { inapropriado" em teatro } \\
\text { londrino }\end{array}$ & 12 & 31 & 248 & 1 & 1 & 70 \\
\hline
\end{tabular}


Conforme aponta a tabela3, a matéria sobre as acusações contra Harvey Weinstein foi construída com 453 palavras e 4 ilustrações, uma foto apresentando o acusado e o restante de vítimas diferentes. Além disso, são grifados em negrito dois hiperlinks que possibilitam ao leitor ter acesso para mais informações sobre o caso de acordos não divulgados com mulheres envolvendo "assédio sexual e contato físico indesejado" e a respeito do pedido desculpas após as primeiras denúncias que surgiram contra ele.

Por outro lado, o corpo do texto da matéria sobre Kevin Spacey foi construído com um pouco mais que a metade desse número, por meio de 248 palavras e 1 ilustração, em que aparece somente o acusado. Em relação ao único hiperlink grifado da matéria, ele permite saber mais sobre as "alegações feitas por um ex-funcionário de que Kevin Spacey praticou assédio sexual contra jovens no Old Vic".

Já a construção das matérias a partir do uso das terminologias pelo portal foi analisada através de cinco categorias criadas no trabalho, visando investigar se e como as manifestações simbólicas relacionadas ao crime de assédio sexual foram divulgadas. Perante o Código Penal brasileiro, o assédio sexual se respalda em:

Art. 216-A. Constranger alguém com o intuito de obter vantagem ou favorecimento sexual, prevalecendo-se o agente da sua condição de superior hierárquico ou ascendência inerentes ao exercício de emprego, cargo ou função: Pena - detenção, de 1 (um) a 2 (dois) anos (GRECO, 2015, p. 527).

De acordo com Greco (2015), este crime acontece quando um agente homem ou mulher visa obter alguma vantagem ou favorecimento sexual com a vítima. Para ser enquadrado como assédio sexual, deve existir um vínculo de trabalho entre os sujeitos, em que o agente social se prevalece da sua condição de superior hierárquico ou ascendência para alcançar algum intuito sexual. Nestes casos, não acontece uma manifestação física de violência, já que não chega as vias de fato e não utiliza da força física contra a vítima, do contrário seria enquadrado como outro crime perante a legislação penal brasileira. Apesar disso, não se anula o fato de ser exercida uma violência simbólica através do constrangimento ou da intimidação, baseados na ameaça ao exercício do emprego, cargo ou função da vítima. Greco (2015) exemplifica os casos, apontando como acontecem através da perseguição com propostas, insistências e importunação à vítima tendo o cunho sexual.

A busca pelos termos utilizados na construção das matérias também tornou possível refletir a divisão do patriarcado apresentada por Tiburi (2018, p. 96), quando menciona que os homens e o poder estão de um lado, enquanto as mulheres (também abrangendo transexuais homens ou mulheres, travestis e homossexuais) e a violência estão no outro. Sendo assim, a pesquisa procurou destacar os seguintes pontos: 
- Termos que fazem menção às vítimas - visando reconhecer como as vítimas de assédio sexual foram citadas nas matérias e os adjetivos utilizados;

- Termos que fazem menção à divulgação dos crimes - visando reconhecer como o portal de notícias menciona a denúncia de crimes de assédio sexual;

- Termos que fazem menção aos atos dos crimes - visando reconhecer como o portal de notícias menciona e caracteriza os atos e/ou as manifestações simbólicas de assédio e agressão sexual;

- Termos que fazem menção aos acusados - visando reconhecer como os acusados de assédio sexual foram citados e os adjetivos utilizados;

- Termos que fazem menção ao comportamento dos acusados - visando reconhecer como o comportamento dos acusados de assédio sexual é qualificado nas matérias.

Tabela 2 - Termos utilizados nas matérias analisadas do G1

\begin{tabular}{|c|c|c|c|c|}
\hline \multirow[b]{2}{*}{$\begin{array}{l}\text { Termos que fazem } \\
\text { menção }\end{array}$} & \multicolumn{2}{|c|}{ Harvey Weinstein } & \multicolumn{2}{|c|}{ Kevin Spacey } \\
\hline & Termos & $\begin{array}{l}\text { Número de vezes em } \\
\text { que aparece }\end{array}$ & Termos & $\begin{array}{c}\text { Número de vezes em } \\
\text { que aparece }\end{array}$ \\
\hline \multirow[t]{3}{*}{ Às vítimas } & Mulheres & 4 & Homens & 3 \\
\hline & Atriz(es) & 8 & Jovens atores & 1 \\
\hline & $\begin{array}{l}\text { Atrizes ainda mais } \\
\text { conhecidas }\end{array}$ & 1 & Funcionários & 1 \\
\hline \multirow[b]{2}{*}{$\begin{array}{l}\text { À divulgação dos } \\
\text { crimes }\end{array}$} & -- & -- & Acusações & 1 \\
\hline & Denúncia(s) & 2 & $\begin{array}{l}\text { Denúncia (s), } \\
(-10 s)\end{array}$ & 2 \\
\hline \multirow{3}{*}{$\begin{array}{l}\text { À divulgação dos } \\
\text { crimes }\end{array}$} & Relato (s); relatam & 3 & Relatos & 1 \\
\hline & $\begin{array}{l}\text { Diz; dizem; disse; } \\
\text { disseram }\end{array}$ & 13 & Alegaçõos & 1 \\
\hline & -- & -- & Comunicar & 1 \\
\hline \multirow{6}{*}{$\begin{array}{l}\text { Aos atos dos } \\
\text { Crimes }\end{array}$} & Assediada(s) & 3 & -- & -- \\
\hline & Assédio (Sexual) & 4 & Assédio (sexual) & 1 \\
\hline & Colocar a mão (tocar) & 2 & Passar a mão & 2 \\
\hline & $\begin{array}{c}\text { Contato físico } \\
\text { indesejado }\end{array}$ & 1 & $\begin{array}{c}\text { Tocava [entre as } \\
\text { pernas] }\end{array}$ & 1 \\
\hline & Experiência ruim & 1 & -- & -- \\
\hline & Massagens & 1 & & \\
\hline \multirow{3}{*}{ Aos acusados } & Produtor & 5 & Ator & 2 \\
\hline & -- & -- & Diretor & 3 \\
\hline & $\begin{array}{c}\text { Produtor vencedor do } \\
\text { Oscar }\end{array}$ & 1 & Grande estrela & 1 \\
\hline \multirow{3}{*}{$\begin{array}{l}\text { Ao comportamento do } \\
\text { acusado }\end{array}$} & $\begin{array}{c}\text { Comportamento contra } \\
\text { mulheres }\end{array}$ & 1 & $\begin{array}{c}\text { Comportamento } \\
\text { inapropriado }\end{array}$ & 3 \\
\hline & Inaceitável & 2 & Inaceitável & 2 \\
\hline & Bullying & 1 & Bullying & 1 \\
\hline
\end{tabular}

A partir dos dados da tabela3, se confere que apesar de ambas matérias tratarem de 
assédio sexual, o termo "violência" não é abordado. Além disso, as vítimas não são nomeadas dessa forma, sendo utilizados seus próprios nomes ou termos como "mulher" e "homem", "atriz" e "ator", junto as suas flexões no plural. Duas qualificações também surgem, "atrizes ainda mais conhecidas" e "jovens atores”. Em relação a Harvey Weinstein e Kevin Spacey, os termos "acusado" ou "suspeito" não foram meios para mencioná-los, tendo sido utilizadas expressões relacionadas com a posição profissional deles, Harvey foi descrito como "produtor" e "produtor vencedor do Oscar" e Kevin como "ator", "diretor" e "grande estrela".

A tabela3 também permite verificar como a matéria a respeito das denúncias contra Harvey possui um teor criminal mais informal, em que foram utilizadas algumas das flexões dos termos "denúncia", "relato" e "dizer". Sobre os atos dos crimes, o portal de notícias aponta como as vítimas foram "assediadas", sofreram "assédio (sexual)", como o acusado foi responsável por "colocar a mão (tocar)", proporcionar uma "experiência ruim", realizar "contato físico indesejado" e sugerir "massagens".

Enquanto a matéria relacionada a Kevin Spacey trouxe termos mais formais, como "acusações", "denúncia”, "relatos", "alegações” e "comunicar", juntamente de algumas de suas flexões. Em relação aos atos dos crimes, o portal de notícias aponta a ocorrência de "assédio (sexual)" e como o acusado "tocava [entre as pernas]" e foi responsável por "passar a mão". Por fim, em ambas as matérias os comportamentos dos acusados são qualificados como inaceitáveis e surge também o termo "bullying”. No caso de Harvey Weinstein, ainda se confere a expressão "comportamento contra mulheres" e de Kevin Spacey, "comportamento inapropriado".

\section{Análise Qualitativa}

Antes da análise qualitativa no corpo do texto das matérias, os títulos já apresentam duas ponderações que merecem destaque e estão relacionadas a utilização dos verbos "dizer" e "receber". No caso da matéria Angelina Jolie, Gwyneth Paltrow e mais atrizes dizem a jornal que foram assediadas por Harvey Weinstein, o portal de notícias aponta que atrizes "dizem" terem sido assediadas, de acordo com o dicionário Michaelis, o verbo "dizer" tem como significado o ato de "exprimir por palavras, faladas ou escritas, algo a alguém". Nesse contexto, as atrizes não estão apenas dizendo algo trivial, mas "alegando", "acusando" ou "denunciando" terem sido vítimas de um crime, por conta disso a atitude delas não deve ser expressada com a utilização de um verbo que está suavizando a situação.

Em relação a matéria Kevin Spacey recebe mais 20 acusações de "comportamento 
inapropriado" em teatro londrino, a postura do portal de notícias ao escolher esse título já se mostra diferente, pois ao utilizar do verbo "receber" o discurso não diz mais respeito às vítimas, mas ao fato do ator ser o sujeito ativo, aquele que está exercendo a ação. Como também aponta o dicionário, o verbo apresenta o significado de "aceitar alguma coisa que lhe é dado, enviado, dirigido etc", logo interpreta-se que o ator "recebeu" as acusações, como uma ação concluída e que inviabiliza a possibilidade de um contexto alternativo para o público refletir somente a partir da leitura do título, restringindo a visão de uma negação desses comportamentos ou até mesmo a falta de um pronunciamento do acusado.

Outra ponderação diante da construção do título dessa matéria está relacionada a utilização da expressão "comportamento inapropriado" para fazer menção aos crimes de assédio sexual realizados por Kevin Spacey contra o sexo masculino, partindo do princípio de que as determinações sociais (os comportamentos "apropriados" e "inapropriados") para os gêneros resultam das expectativas construídas socialmente, o discurso pode atuar como meio para convencionar essas representações sociais que servem como sujeitos espelhos. Butler (2003, p. 29) destaca que o gênero se comporta como "um ponto relativo de convergência entre conjuntos específicos de relações, cultural e historicamente convergentes". De modo que essas concepções acerca dos gêneros são indissociáveis dos aspectos políticos e culturais de determinado lugar e época, ou seja, a cultura machista também pode influenciar neste processo que busca pré-determinar o comportamento feminino e masculino.

Posto isso, quando o portal de notícias utiliza dessa expressão no título de uma matéria que trata a respeito de assédio sexual e homossexualidade, ele se torna responsável por promover a ideia de que esse "comportamento inapropriado" pode ter relação com a orientação sexual do ator. Ainda, sendo possível que o público faça a leitura somente do título da matéria e relacione ao conhecimento da orientação sexual do acusado, sem haver a leitura completa do texto. Por meio dessa atitude, o veículo ratifica o preconceito da cultura machista de que quando um homem sente atração pelo mesmo sexo/gênero está apresentando um comportamento inapropriado.

Em ambos os títulos, os termos "acusar", que significa "imputar falha, culpa ou crime a alguém ou a si mesmo" ou "denunciar", que significa "revelar(-se) à justiça; apontar alguém ou a si mesmo como autor de um crime ou delito", configuram-se como verbos mais adequados à situação.

A respeito das linhas de apoio das matérias, ambas apresentam denúncias de assédio sexual contra os acusados, em formato de citação direta pelas vítimas ou testemunhas dos crimes. Durante a análise, também se verifica o surgimento de outra qualificação para o 
comportamento dos acusados, mencionado pela atriz Angelina Jolie contra Harvey Weinstein - o "comportamento inaceitável", apesar dessa expressão ter sido pontuada pela vítima, ela apareceu somente duas vezes na construção da matéria e sempre integrando a citação direta da denúncia da atriz (uma vez na linha de apoio e uma vez no corpo do texto). Enquanto a expressão "comportamento inapropriado", direcionada para o ator Kevin Spacey, apareceu 3 vezes: duas vezes integrando o texto jornalístico e uma vez no texto do comunicado do teatro londrino (uma vez no título e duas vezes no corpo do texto), comprovando como o veículo de comunicação se apropriou da expressão utilizada pela fonte para a construção da matéria.

Em relação ao corpo do texto das notícias, o desmerecimento para com as vítimas é evidenciado nas abordagens jornalísticas. Começando por um trecho da matéria acerca do acusado Harvey Weinstein, em que o portal de notícias menciona como os "novos relatos" que surgiram vieram de "atrizes ainda mais conhecidas", de certa forma desqualificando a "lista inicial" de denúncias. Em seguida, a frase é finalizada dizendo que essas atrizes "corroboram a denúncia", abrindo espaço para reflexão de como a veracidade das denúncias de assédio sexual é alimentada pela notoriedade que possuem as suas vítimas.

\section{A lista inicial tinha as atrizes Ashley Judd e Rose McGowan. Os novos relatos, com atrizes ainda mais conhecidas, corroboram a denúncia.}

Figura 5 - Captura de tela do trecho da matéria analisada referente a Harvey Weinstein Fonte: G1

O desmerecimento também é exibido na narrativa do contexto em que a atriz Gwyneth Paltrow sofreu o assédio sexual pelo produtor, já que durante a apresentação dos acontecimentos pelo portal de notícias é evidenciado como a vítima foi contratada por Harvey Weinstein para participar do filme "Emma" (1996), mas mesmo antes de começarem as filmagens, o produtor assediou sexualmente a atriz, através de um convite para que fossem juntos ao quarto dele. Na matéria, o assédio é abordado com o termo "sugeriu", "sugeriu que eles fossem ao quarto para fazer massagens”.

\section{Gwyneth disse que foi assediada aos 22 anos, quando foi contratada para fazer o filme "Emma" (1996). Antes das filmagens, ela foi chamada à suíte do produtor em um hotel em Beverly Hills. A atriz diz que ele colcocou a mão nela e sugeriu que eles fossem ao quarto para fazer massagens.}

Figura 6 - Captura de tela do assédio sexual denunciado por Gwyneth contra Harvey Weinstein Fonte: G1 
Em seguida a matéria aponta que a atriz "recusou o assédio", quando na verdade a atriz recusou a proposta inserida no assédio de Harvey Weinstein, em razão de que o assédio não poderia ter sido recusado, pois o acusado já tinha agido de forma criminosa. Por meio dessa abordagem do portal de notícias, ele finda por reduzir a intenção e anular o crime de assédio sexual, pois a narrativa sugere que se o acusado não alcançou o resultado esperado, o crime pode ser desconsiderado.

Não importa o que a vítima fez antes ou depois do crime. Se decidiu perdoar o agressor ou se quis ir à uma festa: nada disso anula o que ela sofreu. As mulheres que decidem denunciar a violência que sofreram são colocadas sob um holofote e todos os seus passos são acompanhados na busca de sinais que provem que a sua versão dos fatos é uma mentira (ONG THINK OLGA, 2016, p. 21).

Como mencionado pela ONG Think Olga, a narrativa de crimes de gênero pelos veículos de comunicação pode resultar não somente no desmerecimento da vítima, como também do próprio crime. Nesse âmbito, os jornalistas também devem estar atentos para que durante a descrição dos fatos não acabem abrindo espaço para a interpretação de que o comportamento da vítima é uma justificativa para o crime. Tiburi (2018, p. 38) destaca que a sociedade apresenta o hábito de julgar a mulher como responsável por incitar os homens à violência, pois “a lógica patriarcal sempre culpa as mulheres pelos erros dos homens - sem assumir que os homens podem ser culpados pelos erros das mulheres". Dessa forma, são construídas justificativas para a existência de atos violentos contra o gênero feminino, tendo como base o comportamento da própria vítima e não do agente social.

Durante a contextualização do assédio sexual realizada pelo portal de notícias, ainda surge outro ator social - o namorado da vítima na época. A partir disso, a espetacularização do caso acontece através da narrativa de um "confronto" entre o namorado da vítima e o agressor, conforme mostra a Figura 7.

\footnotetext{
A atriz diz que recusou o assédio e contou ao seu namorado na época, Brad Pitt. Ele teria confrontado o produtor e dito para que ele nunca mais tocasse nela. Harvey pediu para que ela não contasse nada a ninguém. "Eu achei que ele fosse me demitir", ela disse. Brad Pitt confirmou o relato ao "New York Times".
}

Paltrow diz que Weinstein ainda ligou e brigou com ela após ser confrontado por Pitt. "Ele gritou comigo por muito tempo. Foi brutal", Ela diz que teve medo de perder o papel em "Emma", e insistiu para ele que mantivesse uma atitude profissional.

Figura 7 - Captura de tela do assédio sexual denunciado por Gwyneth contra Harvey Weinstein Fonte: G1

Nos novos parágrafos que surgem acontecem mais duas divergências na abordagem 
utilizada pelo portal de notícias, começando pela frase que aponta como "Harvey pediu para que ela não contasse nada a ninguém" quando de fato o agressor pediu para que ela não "denunciasse" o episódio de assédio que sofreu. Principalmente, ao considerar a ameaça intricada no pedido, tendo em vista o relato da vítima dizendo que "eu achei que ele fosse me demitir", logo ela se sentiu ameaçada e, por conta disso, não foi apenas um "pedido para que ela não contasse".

Em seguida, a próxima divergência aparece quando a matéria aponta que "Weinstein ainda ligou e brigou com ela após ser confrontado por Pitt”, a partir disso a conduta do acusado também deveria ser considerada como assédio moral. Principalmente, se considerado o depoimento utilizado para encerrar o contexto de assédios sofridos pela vítima, em que ela denuncia as atitudes de "bullying e punição" que a seguiram na sua carreira. Dessa forma, comprovando como o assédio sexual soma-se as diversas dificuldades que as mulheres enfrentam para conseguirem escapar das marcações que são impostas ao gênero feminino e para que consigam alguma independência financeira.

\section{"Esperavam que eu mantivesse o segredo". Durante sua carreira desde então, Paltrow diz que Harvey alternava em relação a ela atitudes "generosas, apoiadoras e de defesa", com "bullying e punição".}

Figura 8 - Captura de tela do assédio sexual denunciado por Gwyneth contra Harvey Weinstein Fonte: G1

Em relação ao conteúdo da matéria acerca do acusado Kevin Spacey, surpreende as discordâncias entre o título e o corpo do texto, começando pelo fato da chamada apontar que o ator recebeu mais de 20 acusações de comportamento inapropriado, contrariando a informação apresentada no decorrer do texto a respeito de ter sido teatro Old Vic o responsável por receber as denúncias contra o Kevin. A reflexão sobre quem realmente recebeu as denúncias acaba por anular o caráter sensacionalista do título em cima do acusado.

\section{O teatro Old Vic, de Londres, afirmou nesta quinta-feira (16) que já recebeu 20 novas denúncias de comportamento inapropriado contra o ator Kevin Spacey, que foi diretor artístico do local por 11 anos. As informações são do jornal britânico "The Guardian". \\ Figura 9 - Captura de tela da matéria com denúncias contra Kevin Spacey Fonte: G1}

Além disso, a escolha em abordar as denúncias de assédio sexual com a expressão 
"comportamento inapropriado" no título da matéria e no corpo do texto culmina em minimizar tanto o caráter criminoso dos fatos quanto a atitude do acusado, podendo ter sido essa uma escolha proposital de palavras para o comunicado da instituição, buscando não colaborar com a polêmica entorno do Teatro Old Vic. Consequentemente, a reprodução dessa expressão pelo portal de notícias acabou somando-se e colaborando com a intenção contida no discurso do comunicado.

\section{Em comunicado, o Old Vic afirma que havia um "culto à personalidade" em torno de Kevin Spacey durante seu tempo como diretor do teatro, e que sua fama impediu jovens atores e funcionários de denunciá-lo.}

Figura 10 - Captura de tela da matéria com denúncias contra Kevin Spacey Fonte: G1

A matéria também evidencia as justificativas que foram apresentadas através do comunicado do Old Vic. De acordo com as informações, as denúncias não foram realizadas anteriormente por conta de existir um "culto à personalidade", o que somente resulta em colocar a culpa em cima das próprias vítimas e a notícia ainda complementa dizendo que a fama de Kevin Spacey "impediu jovens atores e funcionários de denunciá-lo”, seria correto dizer que a posição social do acusado intimidou as vítimas, em vista de que ele era o diretor do teatro onde elas trabalhavam. A apresentação dos fatos de forma mais sucinta poderia ter explicado diretamente o porquê de não terem existido denúncias anteriormente, sem depositar a culpa nas vítimas e sim, no contexto onde elas estavam inseridas.

Essa transposição da culpa para as vítimas ainda é apresentada quando mencionado que o presidente pede "desculpas a todos que se sentiram incapazes de comunicar o que aconteceu", ressaltando o desmerecimento para com as vítimas ao chamá-las de incapazes. Ademais, o termo “comunicar" deveria ser substituído por “denunciar”, pois já está explícito que as vítimas na verdade se sentiram ameaçadas.

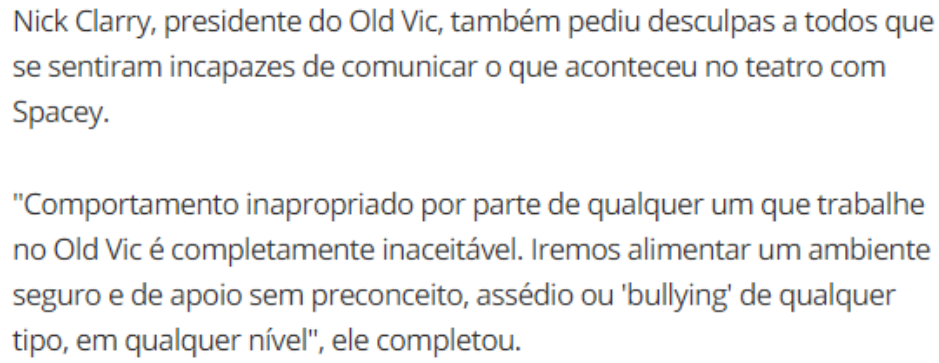

Figura 11 - Captura de tela da matéria com denúncias contra Kevin Spacey Fonte: G1 
A partir das análises de conteúdo que foram realizadas em ambas as matérias selecionadas para a pesquisa, tornou-se possível pontuar alguns dos aspectos presentes na abordagem jornalística do portal de notícias G1. Podendo ser ressaltado o comportamento do veículo diante das informações que são trazidas pelas fontes, pautado em realizar a apropriação e a veiculação exata da interpretação dos acontecimentos pelas suas fontes, lançando mão de uma abordagem crítica diante dos fatos. Consequentemente, podendo acarretar na reprodução de um discurso que pode estar carregado de violência e tendenciosidades, pertencentes à fonte que está servindo de fundamento da matéria.

\section{Discussão das análises}

Nos casos que foram apresentados no trabalho, o tema "assédio sexual" obteve forte repercussão pelos veículos digitais e pelo público, em vista dos atores sociais que estavam envolvidos nos crimes. Do contrário, como analisado nos estudos de Traquina (2005), essa violência não costuma ser caracterizada pelo impacto causado na sociedade quando midiatizada, por conta do seu caráter ambíguo enquanto violência subjetiva e objetiva, que acarreta na dificuldade do público em entender como a violência está presente. Em vista disso, se torna fundamental que os veículos jornalísticos atuem em favor do esclarecimento do público, apresentando como se configura a manifestação simbólica da violência nesses casos, a exemplo da perseguição com propostas, insistências e importunação à vítima tendo o cunho sexual, como apontado por Greco (2015). Ou seja, esclarecendo como a linguagem pode substituir a violência direta pela imposição do medo e pela formação da ameaça, comportamento que foi analisado nos estudos de Žyžek (2009).

A partir das análises apresentadas, o trabalho conferiu como as matérias escolhidas utilizaram de algumas das potencialidades do jornalismo digital, como título, linha de apoio, texto, ilustrações e hiperlinks. Porém, mesmo com a possibilidade de um texto com maior aprofundamento no ambiente online, foi averiguado que não houve o incentivo ou a iniciativa para que a abordagem sobre os casos fosse realizada em prol da reflexão acerca do tema e do combate às violências.

A escolha desses profissionais em não exercerem um posicionamento contrário à violência pode estar colaborando com a persistência da violência simbólica, pois oportuniza que o silêncio seja interpretado como uma visão naturalizada dos crimes, ou seja, como sendo os fatos condizentes com um ambiente de normalidade. Nesse âmbito, os jornalistas que atuam diretamente com a produção da linguagem, seja ela escrita, falada ou de sinais, devem 
estar atentos para não atuarem de forma passiva, principalmente ao utilizarem de terminologias inadequadas ou que não propiciem o devido esclarecimento. Assim, buscando evitar que ocorra uma interpretação errônea dos atos de violência e ampliando a possibilidade de discussão a respeito dos problemas sociais que as matérias estão abordando.

Com base nisso, os jornalistas devem procurar reverter esse caráter superficial que é designado para as matérias que abordam sobre casos de assédio e/ou agressão sexual. Como ressalta Correia (2003, p. 9) "nada impede que o hipertexto e a utilização de tecnologias multimedia não possam ser indutoras de processos onde se verifiquem um acréscimo de rigor e de aprofundamento". Visto que, dependendo da maneira com que esses atos de violência são apresentados ao público, pode resultar na síntese dos acontecimentos em meras queixas e reclamações das vítimas. Para superar essa percepção deve ser destaca a necessidade de tornar o conteúdo mais aprofundado, de forma a apresentar informações de utilidade pública a respeito do tema, por exemplo, explicando como as vítimas podem proceder diante desses casos no Brasil, apresentando estatísticas sobre assédio sexual no trabalho, bem como números de telefone para casos semelhantes de denúncia. Neste sentido, a ONG Think Olga (2016) sugere que caso o assunto das matérias esteja relacionado à violência contra a mulher, os veículos de comunicação poderiam informar o número de telefone referente à Lei Maria da Penha, o Disque 180. No caso de crimes de assédio sexual, as matérias também poderiam apoiar as vítimas, informando sobre a possibilidade de realizar as denúncias ao Ministério Público do Trabalho.

Nas matérias que foram analisadas no trabalho, em relação à indústria do entretenimento norte-americana, os casos poderiam ter sido explorados através de um formato mais criminal/investigativo e menos especulativo, por meio da abordagem sugerida pelo trabalho seria possível levar ao público o conhecimento acerca do tema e promover a aproximação com a realidade de demais sujeitos que podem estar inseridos em contextos semelhantes. Assim, também buscando promover mudanças no contexto histórico-cultural dos indivíduos - responsável pelo fundamento para o processo de manifestação da violência, bem como pelas interpretações a serem concebidas, como destacado por Porto (2002).

Apesar das convergências entre a violência e o jornalismo, principalmente em relação à busca pelo sensacionalismo através da espetacularização para atrair a atenção do público, também deve-se refletir a falta de intencionalidade desses profissionais durante a abordagem de conteúdos com o tema da análise. Pois, como pontuado nos estudos de Žyžek (2009), a respeito da violência objetiva, existe a possibilidade de os sujeitos corroborarem inconscientemente com as manifestações desse fenômeno, por conta de estarem inseridos num 
contexto histórico-cultural que tanto está baseado quanto fundamenta o seu próprio caráter violento, a exemplo do que acontece na cultura machista e homofóbica.

Por meio das análises realizadas, o trabalho reflete como a profissão pode se configurar como um dos domínios sociais específicos apontados por Bourdieu (2002), que se associa as questões de poder e dominação na sociedade. Além de apresentar como o jornalismo segue em contrapartida as expectativas de uma atuação em prol do serviço público, como sugerido nos estudos de Traquina (2005), em vista de que a prática jornalística continua se manifestando a favor da naturalização do estado das coisas. Logo, quando esses profissionais colaboram com a reprodução do discurso, também continuam exercendo um trabalho para o poder, mesmo não sendo mais de forma intricada com questões políticas.

Com base nisso, se torna necessária a visão crítica desses profissionais para com a sua própria realidade e de demais sujeitos, principalmente, no momento de considerar o que deve ser ressaltado ou evitado durante a construção das notícias que tratam acerca do tema da análise, pois apesar de existir a cobrança para que as notícias sejam publicadas cada vez mais instantaneamente no meio digital, os materiais produzidos se mantêm disponibilizados ao público no acervo do portal de notícias. Dessa forma, o discurso jornalístico se mantém eternizado nesse espaço, somando visualizações ao longo do tempo e continuadamente reproduzindo esse conteúdo. Logo, os jornalistas devem buscar reiterar o papel social que diz respeito a profissão e não o enquadramento num padrão de produção e discurso, que não agregam o devido valor, conhecimento e reflexão para a sociedade.

Mesmo havendo a possibilidade de o contra-agendamento da mídia ser um meio de trazer temas que não costumam serem veiculados, se deve refletir qual é a abordagem que será conferida para as notícias, pois ela ainda depende da intenção do veículo jornalístico para atuar a favor do debate e do esclarecimento. Dessa forma, apesar do tema de um contraagendamento partir de "uma mobilização social ou parte de um plano de enfrentamento de um problema, corporativo ou coletivo" (SILVA, 2007, p. 84-85), a tentativa de impor o debate acerca de determinado tema pode ser falha, como apresentado pela análise do trabalho e discutido por Blay (2008):

O segredo da violência é desvendado cada vez mais para o conhecimento do público. A imprensa, que anteriormente tinha uma posição de desconfiança para com a mulher, enfatizando por vezes que ela era a culpada da violência e da própria morte, progressivamente foi se modificando, tornando-se investigativa e abandonando os antigos prejulgamentos que condenavam a vítima. (BLAY, 2008, p. 216)

A partir do apontamento da autora verifica-se que mesmo que certo tema de clamor social seja veiculado, ele pode se limitar a reprodução do discurso instituído e somente servir 
para a reprodução do conservadorismo, em relação aos papéis e à violência de gênero. Nesse caso do fomento da culpabilização das vítimas mulheres, se confere que em meio a sociedade dominada pela ordem patriarcal, a imprensa atuou a favor da reprodução da dominação masculina. Frente a isto, conforme a conclusão de Blay (2008), outro modelo de veiculação busca confrontar essa reprodução do conservadorismo na mídia, atuando através da investigação e levando ao público o conhecimento acerca das violências contra a mulher, entre tantas outras cometidas contra o gênero feminino. Em relação ao tema deste trabalho, durante a coleta, a organização e a busca pelas matérias que seriam selecionadas para a análise de conteúdo, ficou perceptível como o portal de notícias G1 não tratou os casos de forma devidamente criminal e não apresentou informações de utilidade pública nos conteúdos que abordam a respeito de assédio sexual, contrariando a evolução jornalística mencionada pela autora.

Este aspecto também corrobora com a análise de Bertolini (2016) quando ressalta as relações entre o jornalismo e o sistema de exclusão, apresentados por Foucault (1996). Nesse sentido, o autor acredita que "ao dar visibilidade a determinados discursos, a imprensa potencializa, consolida e constrói poderes" (BERTOLINI, 2016, p. 47). Com base em seus estudos, a construção desses poderes pode ser realizada através do potencial de "interdição" que está presente nas atividades jornalísticas, em vista de que, além da escolha do que será noticiado, esses profissionais são responsáveis por apontar quem irá dizer e o que será dito nas matérias, assim interditando e limitando outras oportunidades de abordagem.

Logo, deve-se reforçar que o jornalismo atue em prol do serviço público, por meio da escolha de fontes relevantes ao tema tratado e de ambas as partes, incentivando um pensamento crítico no público e combatendo as violências presentes nos contextos sociais. Por meio disso, consolidando o apontamento de Bourdieu (2002), sobre como os mesmos responsáveis por manter a "eternização" da dominação masculina podem exercer o seu trabalho para o desaparecimento progressivo da cultura machista. Neste caso, buscando romper com a reprodução desse discurso por essa instituição, para que o seu potencial sirva como fomento ao conhecimento e atue de forma positiva para toda a sociedade.

\section{Conclusão}

O trabalho pretendeu analisar como é a abordagem dos veículos jornalísticos digitais no Brasil quando noticiam denúncias de assédio sexual, a partir da linha metodológica da análise de conteúdo, para além de verificar como é a abordagem desses veículos na produção 
de notícias sobre o crime, compreender como eles estão utilizando das possibilidades do ambiente online para a construção dos conteúdos. A partir da escolha de duas matérias do portal de notícias G1, a respeito das acusações de assédio sexual contra os norte-americanos Harvey Weinstein e Kevin Spacey, a análise permitiu recolher dados quantitativos e qualitativos de denúncias atuais, veiculadas em um intervalo curto de tempo e que se tratam de relações hétero e homossexuais. Assim, ainda permitindo conferir as semelhanças e diferenças na construção do discurso jornalístico para as notícias.

Em vista disso, o trabalho também teve como objetivos destacar o conceito de violência e apresentar as suas múltiplas formas de manifestação, visando identificar quais são do conhecimento ou não reconhecimento dos sujeitos, bem como as suas características. Nesse âmbito, a pesquisa ainda pretendeu investigar como as manifestações de violência podem ser promovidas em apoio uma a outra e de forma colaborativa na e pela sociedade, sendo destacados os casos de violência de gênero e sexual que estão ligados entre si e à cultura machista, além de todos os dispositivos de poder que promulgam o discurso opressor da dominação masculina. Para analisar a relevância da abordagem dos veículos jornalísticos digitais no Brasil acerca do tema "assédio sexual", a pesquisa também teve a intenção de apontar o potencial presente na construção e reprodução dos discursos, que se caracterizam como ferramentas essenciais para o estabelecimento de dominações sociais. Assim, o trabalho procurou discutir e apresentar as relações existentes entre a violência, o discurso e o jornalismo, especificamente no campo digital.

Com base nesses objetivos, na análise de conteúdo foram elencados e quantificados os termos utilizados pelo portal de notícias para fazer menção às vítimas, aos acusados e à divulgação dos crimes, juntamente as palavras que surgiram para descrever os atos dos crimes e o comportamento dos acusados. Por meio dessa técnica, o trabalho conferiu como um dos mais populares portais de notícias brasileiro não atenta ao uso adequado de terminologias para esses pontos averiguados, ocasionando com que não exista um posicionamento em favor das vítimas e da responsabilidade social do jornalismo para com a sociedade, ainda corroborando com a intencionalidade do discurso de fontes restritas. Tendo sido verificado através da análise do uso limitado das possibilidades de apoio para as vítimas de assédio e/ou agressão sexual, frente ao amplo espaço para divulgação que está presente no ambiente online, o que poderia ter configurado a abordagem dessas notícias para que também tenham o viés de combate a esses tipos de crimes.

Neste trabalho, a pesquisa limitou-se a análise da abordagem jornalística digital para a denúncia de casos de assédio sexual no trabalho, como possibilidade de continuidade ao 
estudo, a pesquisa poderá focar em como os veículos jornalísticos digitais brasileiros estão abordando casos de importunação sexual, após sancionada a Lei n ${ }^{\circ} 13.718$, de 24 de setembro de 2018, que tipifica os crimes de importunação sexual e de divulgação de cena de estupro. Assim, tendo como objetivo comparar antigos e novos casos, bem como analisar e identificar as mudanças na abordagem.

\section{Referências}

Angelina Jolie, Gwyneth Paltrow e mais atrizes dizem a jornal que foram assediadas por Harvey Weinstein. Disponível em: https://g1.globo.com/pop-arte/cinema/noticia/angelinajolie-e-gwyneth-paltrow-dizem-que-foram-assediadas-por-harvey-weinstein-diz-jornal.ghtml. Acesso em: junho de 2018.

BARDIN, L. Análise de Conteúdo. Lisboa: Edições 70, 1995.

BLAY, E. A. Assassinato de Mulheres e Direitos Humanos. São Paulo: Editora 34, 2008.

BERTOLINI, J. Discurso e poder na narrativa midiática: notas entre Foucault e jornalismo. Temática: revista do Núcleo de Arte, Mídia e Informação Digital da UFPR, Paraíba, Ano XII, n. 12, dez. 2016. Disponível http://www.periodicos.ufpb.br/ojs/index.php/tematica/article/view/32057/16604. Acesso em: 14 de out. 2018.

BOURDIEU, P. A dominação masculina. Tradução Maria Helena Kuhner. $2^{\mathrm{a}}$ ed. Rio de Janeiro: Bertrand Brasil, 2002.

FOUCAULT, M. A ordem do discurso. São Paulo: Edições Loyola, 1996.

GRECO, R. Curso de Direito Penal: parte especial, volume III / Rogério Greco. 12a ed. Rio de Janeiro: Impetus, 2015.

Kevin Spacey recebe mais 20 acusações de 'comportamento inapropriado' em teatro londrino. Disponível em: https://g1.globo.com/pop-arte/noticia/kevin-spacey-recebe-mais-20acusacoes-de-comportamento-inapropriado-em-teatro-londrino.ghtml. Acesso em: junho de 2018.

Minimanual do jornalismo humanizado. Pt. I: Violência contra a mulher. 2016. Disponível em: http://thinkolga.com/olga/wpcontent/uploads/2016/06/minimanual_V2.pdf. Acesso em: 13 out. 2018.

TIBURI, M. Feminismo em comum: para todas, todes e todos. $2^{\mathrm{a}}$ ed. Rio de Janeiro: Editora Rosa dos Tempos, 2018.

TRAQUINA, N. Teorias do Jornalismo. $2^{\mathrm{a}}$ ed. Florianópolis: Insular, 2005.

ZIZEK, S. Violência - seis notas à margem. Lisboa: Relógio D’Água Editores, 2009. 